\title{
Evaluation of the impact of COPD severity grading and oxygen saturation on the retinal nerve fiber layer thickness and subfoveal choroidal thickness in COPD patients
}

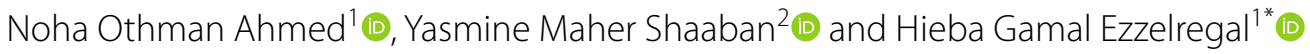

\begin{abstract}
Background: Retinal and choroidal blood vessels are involved in many systemic diseases because they are complex vascular systems. Chronic obstructive pulmonary disease is considered as an inflammatory disease that affects many systems and coexists with several co-morbidities. Systemic inflammation and hypoxia affect the macula, choroid, retinal nerve fiber layer (RNFL), and blood vessels. Ocular co-morbidities have been detected in COPD patients. These can be quantitatively and qualitatively evaluated by Spectral Domain Optical Coherence Tomography (SD-OCT). Enhanced depth imaging OCT (EDI-OCT) is a quite new technique that utilizes light with an extended wavelength. An apparent relation has been found between chronic pulmonary disease and low corneal endothelial cell density preoperatively. So this work aimed to assess the impact of COPD severity grading and oxygen saturation on retinal nerve fiber layer thickness and subfoveal choroidal thickness.

Results: This was a case-control study, recruited 50 COPD patients and another 50 healthy volunteers as a control group. Measuring the thickness of the RNFL (superior, inferior, nasal, and temporal) in the four quadrants as well as the subfoveal choroidal thickness was done to both groups. The RNFL thickness in all quadrants and the SFCT in the COPD group were statistically significantly thinner in comparison to the control group. The RNFL thickness (mean) was $79.16 \pm 10.49 \mu \mathrm{m}$ compared to $96.30 \pm 4.66 \mu \mathrm{m}$ in the control group ( $p$ value 0.001). The SFCT (mean) was $213.12 \pm 25.61 \mu \mathrm{m}$ compared to $354.62 \pm 53.82 \mu \mathrm{m}$ in the control group ( $p$ value 0.001 ). The degree of thinning of the RNFL (superior, inferior, and temporal) and the SCFT was related to COPD (GOLD) stages severity ( $p$ value 0.001). Nasal RNFL was thinned out in all stages of COPD (GOLD) but with no statistical significance ( $p$ value 0.264 ).

Conclusion: The choroid and retina seem to be of the affected tissues during the progressive inflammatory course of COPD. Ocular pathologies should be evaluated in patients with systemic hypoxia. The eye examination for COPD patients can be carried out via a non-invasive procedure such as the OCT and the changes in the RNFL and SFCT thickness could be used as indicators for the severity of COPD.
\end{abstract}

Keywords: Retina, Choroid, Thickness, Hypoxia, Pulmonary disease, Optical coherence tomography

*Correspondence: drhebaezz111213@gmail.com; Hiebagamal24@med.asu. edu.eg

${ }^{1}$ Chest Department, Faculty of Medicine, Ain Shams University, Cairo,

Egypt

Full list of author information is available at the end of the article

\section{Background}

Chronic obstructive pulmonary disease is considered as an inflammatory disease that affects many systems and coexists with several co-morbidities. Retinal and choroidal blood vessels are involved in many systemic diseases because they are complex vascular systems [1]. Ocular 
co-morbidities have been detected in COPD patients. A prominent relationship has been detected between chronic pulmonary disease and the low density of corneal endothelial cells [2]. Hypoxia associated with COPD can have an impact on many organs and tissues in the body. Tissue hypoxia and oxidative stress are the main mechanisms responsible for the general effects of COPD $[2,3]$.

Systemic inflammation and hypoxia affect fine ocular structures, like the macula, choroid, retinal nerve fiber layer, and blood vessels [3]. These structures can be evaluated either quantitatively and/or qualitatively by the spectral-domain optical coherence tomography (SDOCT) [4]. With an extended wave length light, enhanced depth imaging OCT (EDI-OCT) is a quite new technique that provides reliable data about the choroidal morphology and is more elective for choroidal scanning [5-7].

\section{Methods}

This is a case-control study that had been conducted in Ain Shams University Hospitals during the period between July to December 2020, 50 COPD patients without any of the latter exclusion criteria were recruited and another 50 control group who were healthy volunteers from the patients' relatives.

\section{Inclusion criteria}

Patients were selected from those who were coming to do spirometry in the Pulmonary Function Unit in Ain Shams University Hospitals. Patients with a history of COPD who were diagnosed and classified according to the Global Initiative for chronic obstructive lung disease criteria (GOLD) with (the forced expiratory volume in the first second / the forced vital capacity) FEV1/FVC $<0.70$ were included. Control cases were recruited from the relatives of the patients with normal spirometry, no co-morbidities, and within a close age group. Regardless of the right or left eye, the most suitable eye was included in ophthalmological measurements. Eye with visual acuity of 0.8 or better, a spherical refractive error less than $3 \mathrm{D}$ and astigmatism less than $3 \mathrm{D}$, intraocular pressure below $21 \mathrm{mmHg}$, and axial length less than $24 \mathrm{~mm}$ has fulfilled the required measurements.

\section{Exclusion criteria}

Those patients with a history of previous ocular surgery and/or ocular trauma, any previous ocular pathology including uveitis, glaucoma, cataract, senile macular degeneration, macular edema, retinal detachment, and systemic disease that might affect the retina and choroid such as anemia, diabetes mellitus, hypertension, and cardiovascular events including peripheral vascular disorders, thyroid disorders, Cushing disease, cancer and patients who are on antidepressants, steroidal hormone, or mood stabilizers were not included. Any history of exacerbation, colored sputum, or oral corticosteroid within the last month and cases of combined obstructive restrictive lung functions were also excluded.

An informed written consent was collected from all recruited patients before enrollment, and they underwent the following:

Spirometry was performed according to the standard practice [8] using Viasys Health Care spirometer, D-97204, Hoechberg, Germany. Spirometric indices were recorded. The diagnosis of COPD was confirmed and classified according to the Global Initiative for Chronic Obstructive Lung Disease criteria. In patients with FEV1/ $\mathrm{FVC}<0.70$ :

- Mild disease is diagnosed as GOLD 1 with FEV1 $\geq 80 \%$ predicted

- Moderate disease is diagnosed as GOLD 2 with $50 \% \leq \mathrm{FEV} 1<80 \%$ predicted

- Severe $30 \% \leq \mathrm{FEV} 1<50 \%$ predicted

- Very severe disease is diagnosed as GOLD 4 with FEV1 is less than $30 \%$ predicted or FEV1 is lower than $50 \%$ predicted along with hypoxemia [9].

Oxygen saturation was determined by pulse oximetry (oximeter) from the fingertips (Choicemed MD300C29 Dual Color OLED, China) using a finger pulse oximeter to determine oxygen saturation in percentage.

\section{Ophthalmologic examination}

Visual acuity was tested using the Snellen chart. Anterior segment of the eye was examined using slit-lamp biomicroscopy, ocular tension was measured using a noncontact applanation tonometry, and fundus examination was done with the indirect ophthalmoscope. The SDOCT (Spectral-domain, optical coherence tomography, Cirrus HD-OCT model 5000, Carl Zeiss Meditec, AG, Jena, Germany) was used to measure the thickness of the RNFL (superior, inferior, nasal, and temporal) in the four quadrants as well as the subfoveal choroidal thickness.

The procedure of measurement was done by the ophthalmological investigator and revised by the person using the same OCT unit at the time of examination to avoid bais. The scan protocol was done using the optic disc cube $200 \times 200$ scan for RNFL thickness analysis, and using the Enhanced Depth Image Scan (EDIS-OCT) for measuring the choroidal thickness, in which three points were measured, sub-foveal, $3 \mathrm{~mm}$ point nasal, and $3 \mathrm{~mm}$ point temporal to the fovea. 


\section{Ethical consideration}

All the study procedures were consistent with the ethical principles of the Declaration of Helsinki for medical research involving human subjects and were approved by the Faculty of Medicine, Ain Shams University FMASU R $23 / 2020$.

\section{Statistical data analysis}

Data were analyzed using the computer program SPSS (Statistical Package for the Social Science; SPSS Inc., Chicago, IL, USA) release 15 for Microsoft Window (2006). Qualitative variables were presented as percentages and quantitative variables were presented as mean \pm SD. Student's $t$ test and Pearson's correlation coefficient were used as the test of significance; $P$ value less than 0.05 was considered as significant.

\section{Results}

This was a case-control study that recruited 50 COPD patients; 42 (84\%) of them were males with mean age of $49.66 \pm 4.77$ years ranging from 43 to 59 years. All were smokers; 27 (54\%) were active smokers and 46\% were exsmokers. The mean $\mathrm{O}_{2}$ saturation of this COPD group was $89.76 \pm 10.44 \%$ ranging from 69 to $98 \%$; their mean FEV1\% was $54.29 \pm 20.68$ ranging from 22 to $87 \%$. The control group was 50 healthy volunteers recruited from patients' relatives; 24 (48.0\%) were males with mean age of $58.68 \pm 1.58$ years ranging from 55 to 60 years.

The RNFL thickness in all examined parts (superior, inferior, nasal, and temporal) and the SFCT data in the COPD group showed a highly statistically significant decrease in RNFL thickness in comparison to the control group ( $p$ value 0.001 ) (Table 1 ).
The thickness of the superior, inferior, and temporal RNFL thickness was statistically decreased significantly in the patients with higher GOLD classification ( $P$ value 0.001). The nasal RNFL was thinned out in all GOLD stages but with no statistically significant difference among these different groups of GOLD classification ( $p$ value 0.264 ). The SFCT thinning showed a highly statistically significant thinning with the higher GOLD classification ( $P$ value of 0.001 ) (Table 2$)$.

The Pearson's rank correlation coefficient between the subfoveal choroidal thickness and oxygen saturation showed a highly statistically significant positive correlation with $P$ value 0.001 and $r$ (Pearson's correlation coefficient) 0.582 (Fig. 1). Also, a highly statistically significant positive correlation between the average total RNFL thickness and oxygen saturation with $P$ value 0.001 and $r$ (Pearson's correlation coefficient) 0.600 (Fig. 2).

\section{Discussion}

The choroid is a vascular structure that is highly sophisticated and is included with the retinal pigment epithelium and the outer retinal layers blood supply. The choroid circulation can be reflected on the choroidal thickness. It is responsible for the ocular tissues' thermal stability and waste products removal $[10,11]$.

In this study, we highlighted the impact of the different stages of COPD over some ocular structures (the RNFL thickness and the SFCT). The average RNFL thickness was statistically and significantly decreased in the COPD group in comparison to the control group as well as the superior, inferior, nasal, and temporal quadrants ( $p$ value of 0.001 ). The average RNFL thickness (mean) was $79.16 \pm 10.49 \mu \mathrm{m}$ in the COPD group compared to

Table 1 Comparison between the COPD group and the control group regarding RNFL and SFCT parameters

\begin{tabular}{|c|c|c|c|c|c|}
\hline & & $\begin{array}{l}\text { COPD group } \\
\text { (50 cases) }\end{array}$ & $\begin{array}{l}\text { Control group } \\
\text { (50 cases) }\end{array}$ & Test value & $P$ value \\
\hline & & $\mu \mathrm{m}$ & $\mu \mathrm{m}$ & & \\
\hline \multirow[t]{2}{*}{ Superior RNFL } & Mean \pm SD & $93.46 \pm 19.18$ & $113.30 \pm 6.74$ & -6.901 & 0.001 \\
\hline & Range & $58-126$ & $100-126$ & & \\
\hline \multirow[t]{2}{*}{ Inferior RNFL } & Mean \pm SD & $96.96 \pm 15.48$ & $117.58 \pm 12.22$ & -7.394 & 0.001 \\
\hline & Range & $55-131$ & $100-140$ & & \\
\hline \multirow[t]{2}{*}{ Nasal RNFL } & Mean \pm SD & $64.30 \pm 11.14$ & $78.16 \pm 8.72$ & -6.929 & 0.001 \\
\hline & Range & $40-98$ & $65-96$ & & \\
\hline \multirow[t]{2}{*}{ Temporal RNFL } & Mean $\pm S D$ & $61.30 \pm 14.06$ & $75.82 \pm 8.71$ & -6.207 & 0.001 \\
\hline & Range & $40-93$ & $64-90$ & & \\
\hline \multirow{2}{*}{$\begin{array}{l}\text { Average total thickness of } \\
\text { RNFL }\end{array}$} & Mean \pm SD & $79.16 \pm 10.49$ & $96.30 \pm 4.66$ & -10.563 & 0.001 \\
\hline & Range & $58-98$ & $87-108$ & & \\
\hline \multirow[t]{2}{*}{ SFCT } & Mean \pm SD & $213.12 \pm 25.61$ & $354.62 \pm 53.82$ & -16.788 & 0.001 \\
\hline & Range & $130-245$ & $261-443$ & & \\
\hline
\end{tabular}

COPD chronic obstructive pulmonary diseases, $F E V_{1}$ forced expiratory volume in the first second, $R N F L$ retinal nerve fiber layer, SFCT subfoveal choroidal thickness 
Table 2 Correlation between the GOLD classification of COPD patients and the studied eye parameters

\begin{tabular}{|c|c|c|c|c|c|c|c|}
\hline & & $\begin{array}{l}\text { GOLD } \\
\text { I }\end{array}$ & $\begin{array}{l}\text { GOLD } \\
\text { II }\end{array}$ & $\begin{array}{l}\text { GOLD } \\
\text { III }\end{array}$ & $\begin{array}{l}\text { GOLD } \\
\text { IV }\end{array}$ & Test value & $P$ value \\
\hline \multirow{2}{*}{$\begin{array}{l}\text { Superior RNFL } \\
\mu \mathrm{m}\end{array}$} & Mean $\pm S D$ & $113.38 \pm 11.31$ & 99.4211 .79 & 96.4014 .79 & $69.08 \pm 10.27$ & 29.025 & 0.001 \\
\hline & Range & $93-126$ & $64-121$ & $79-120$ & $58-90$ & & \\
\hline \multirow{2}{*}{$\begin{array}{l}\text { Inferior RNFL } \\
\mu \mathrm{m}\end{array}$} & Mean $\pm S D$ & $112.75 \pm 9.90$ & 100.585 .93 & 102.601 .52 & $78.38 \pm 16.53$ & 22.301 & 0.001 \\
\hline & Range & $96-131$ & $90-115$ & $101-104$ & $55-104$ & & \\
\hline \multirow{2}{*}{$\begin{array}{l}\text { Nasal RNFL } \\
\mu m\end{array}$} & Mean \pm SD & $59.75 \pm 8.36$ & $67.38 \pm 11.92$ & $60.20 \pm 3.96$ & $63.00 \pm 12.12$ & 1.370 & 0.264 \\
\hline & Range & $53-75$ & $55-98$ & $57-65$ & $40-80$ & & \\
\hline \multirow{2}{*}{$\begin{array}{l}\text { Temporal RNFL } \\
\mu m\end{array}$} & Mean \pm SD & $70.88 \pm 4.55$ & $68.29 \pm 12.81$ & $53.00 \pm 1.41$ & $45.69 \pm 5.3$ & 19.444 & 0.001 \\
\hline & Range & $68-81$ & $51-93$ & $51-54$ & $40-54$ & & \\
\hline \multirow{2}{*}{$\begin{array}{l}\text { Average total thick- } \\
\text { ness of RNFL } \\
\mu \mathrm{m}\end{array}$} & Mean \pm SD & $89.38 \pm 3.38$ & $84.04 \pm 4.91$ & $78.20 \pm 3.63$ & $64.23 \pm 5.72$ & 61.177 & 0.001 \\
\hline & Range & $85-94$ & $74-98$ & $74-84$ & $58-74$ & & \\
\hline \multirow{2}{*}{$\begin{array}{l}\mathrm{SFCT} \\
\mu \mathrm{m}\end{array}$} & Mean \pm SD & $241.88 \pm 2.30$ & $224.88 \pm 5.42$ & $207.80 \pm 5.12$ & $175.77 \pm 16.08$ & 110.323 & 0.001 \\
\hline & Range & $239-245$ & $218-238$ & $200-214$ & $130-190$ & & \\
\hline
\end{tabular}

COPD chronic obstructive pulmonary diseases, GOLD Global Initiative for Chronic Obstructive Lung Disease, FEV ${ }_{1}$ forced expiratory volume in the first second, RNFL retinal nerve fiber layer, SFCT subfoveal choroidal thickness

$96.30 \pm 4.66 \mu \mathrm{m}$ in the control group. There was also a statistically significant thinning of SFCT in the COPD group compared to the control group ( $p$ value of 0.001). The mean of SFCT was $213.12 \pm 25.61 \mu \mathrm{m}$ in the COPD group compared to $354.62 \pm 53.82 \mu \mathrm{m}$ in the control group. The degree of thinning of the RNFL (superior, inferior, and temporal) and the SFCT was related to COPD (GOLD) stages severity ( $p$ value 0.001 ).

The choroidal thinning could be attributed to reduced blood flow and increased vascular resistance in COPD patients. These results can be correlated with most of the previously done studies [3,12-16].

A study carried by Ozcimen et al. [16] to assess the peripapillary CT of patients with COPD with (EDIOCT). The average measurements of the COPD group $(147.58 \pm 53.53 \mu \mathrm{m})$ were lower than those in the control group $(160.84 \pm 44.73 \mu \mathrm{m})$. Inferior segment thicknesses were significantly thinner than the other segments. The SFCT and RNFL thickness measurements of the COPD group were also lower than those of the control group.

Kocamıs et Zorlu [17] measured the SFCT and the RNFL in patients with COPD who were classified into two groups (stable and exacerbation groups). Statistically, The SFCT of the COPD patients in both groups were found to be thinner than the control group. No significant difference was found between the mean RNFL thickness of the COPD patients and the control group. On the other hand, Ugurlu et al. [18] did not find any statistically significant difference regarding SFCT between COPD and the control groups. They reported thinner RNFL thickness in all quadrants in the COPD group, but only the inferior quadrant data were statistically significant.
They explained these findings to be related to hypoxia and changes in retinal vessel diameter. They claimed that increased retinal vessel diameter in COPD patients may result in a reduction of the RNFL thickness.

Gok et al. [3] evaluated the RNFL thickness and macular CT in patients with COPD using SD-OCT. The average total and nasal RNFL thicknesses in the COPD group were significantly lower than the control group and were thinner in patients with severe COPD. The residual RNFL thickness parameters did not differ significantly between COPD and control groups. The macular CT was thinner at all locations in the COPD group compared with the control group but was not statistically significant. They postulated a link between the disease severity and RNFL thinning proofed by the marked reduction in RNFL thickness in severe COPD patients.

A study was done by Abd El-Naser et al. [15] in two equal groups; a group with mild to moderate COPD and a group with severe to very severe COPD. The SFCT and the RNFL thickness were measured using SD-OCT and compared. The study showed that peripapillary RNFL was significantly thinner in the COPD group than the control group in all quadrants except the superior one. The mean SFCT was statistically significantly thinner in COPD groups than in the control group, and this thinning was more severe with an increase in the severity of COPD.

In a study done by Alim et al. [16] to measure the thickness of the retinal and choroidal layers in COPD patients by using OCT, the SFCT was statistically and significantly affected in the COPD group more than the control group. There were no significant differences between the patients and the control group regarding any mean 


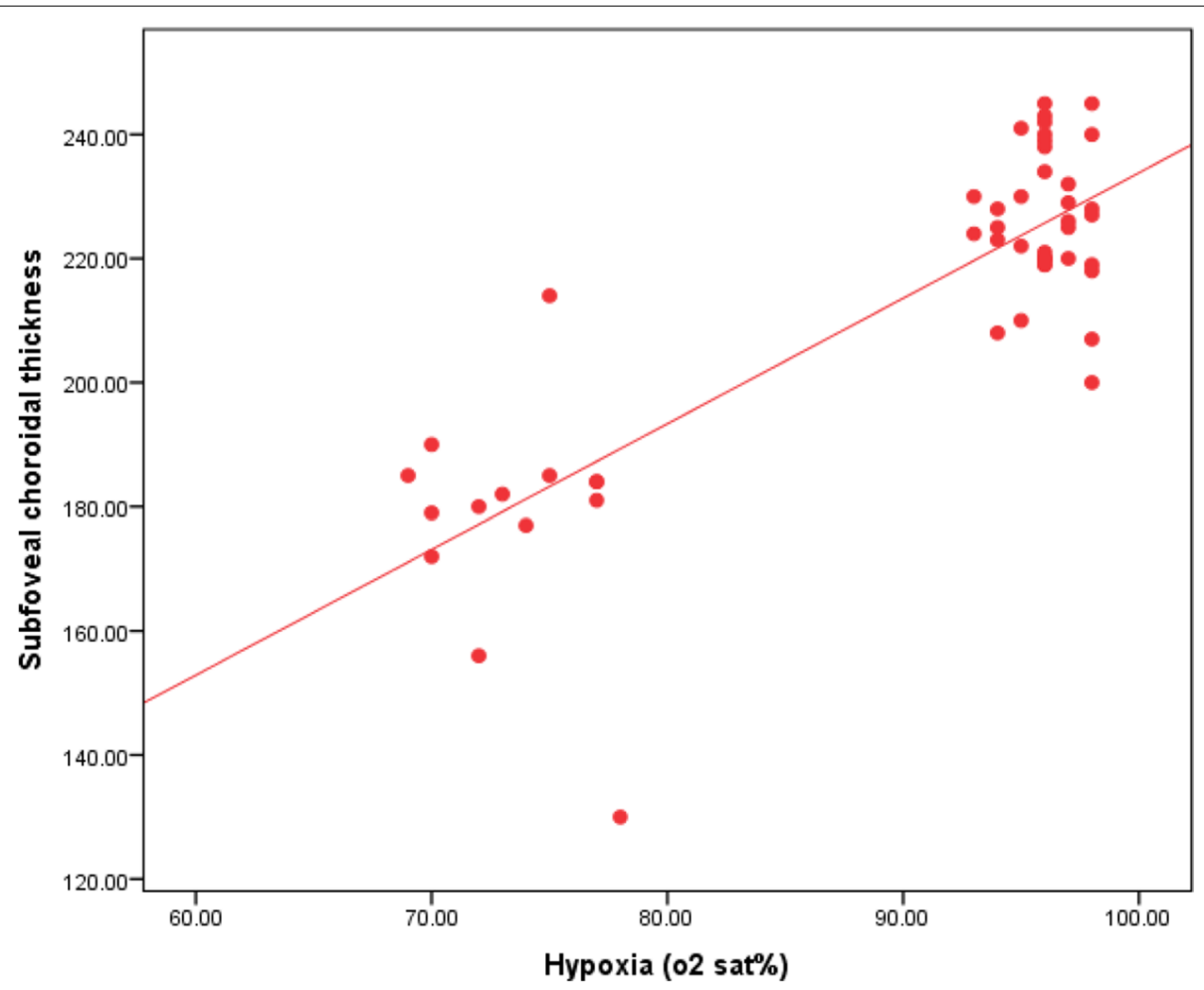

Fig. 1 Correlation between oxygen saturation of the patients and the subfoveal choroidal thickness

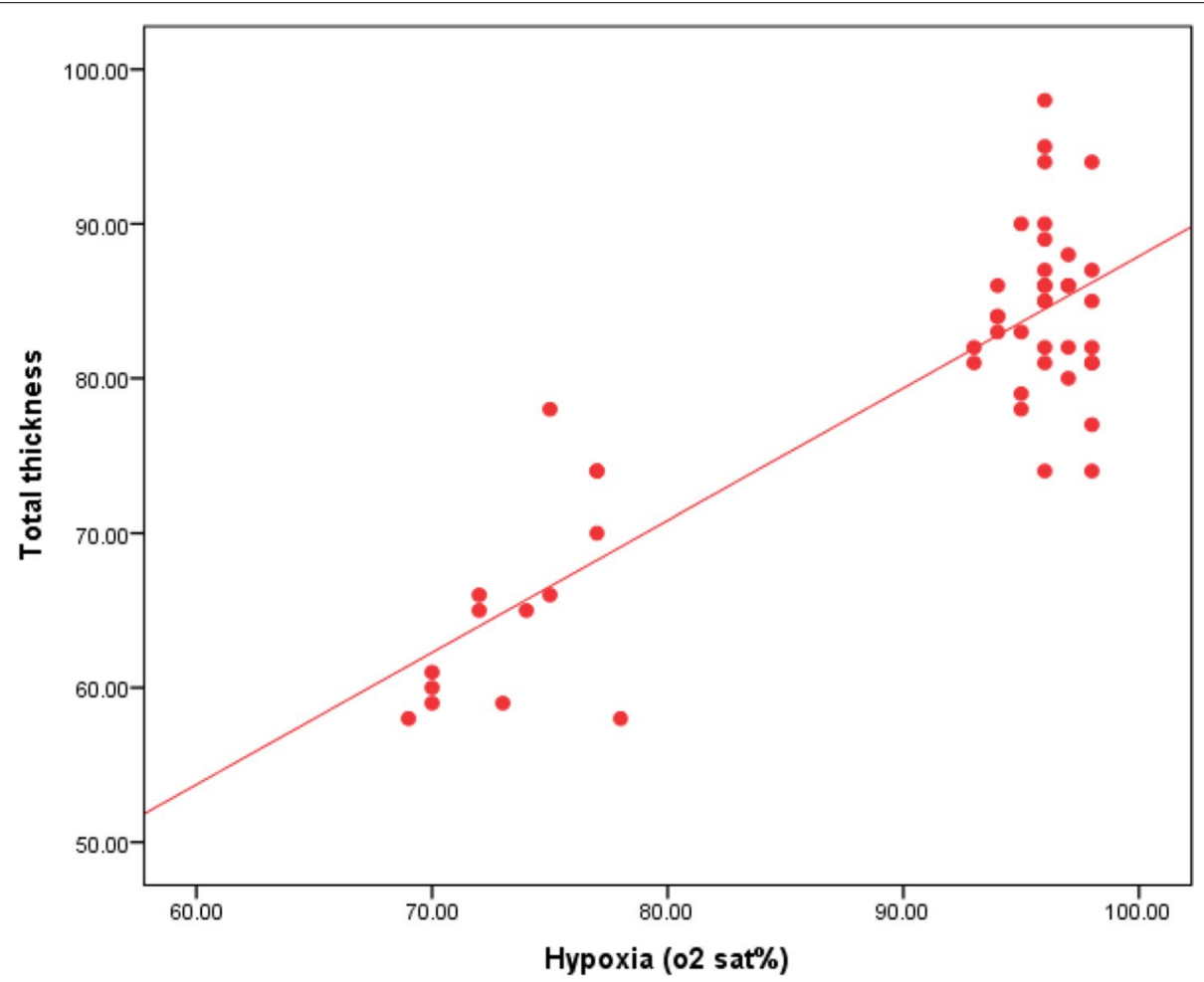

Fig. 2 Correlation between oxygen saturation of the patients and the average total thickness of the retinal nerve fiber layer 
macular thickness and central macular thickness. They concluded that chronic hypoxemia can cause thinning of the choroidal thickness in COPD patients.

On the contrary, a study done by Turan et al. [17] assesses the changes in RNFL in patients with COPD. Parameters of mean and superior quadrant RNFL thickness were found to be significantly thicker in COPD subjects (114.52 $\pm 7.7 \mu \mathrm{m}$ and $141.07 \pm 18.2 \mu \mathrm{m}$, respectively) compared to the control subjects $(107.9 \pm 5.4 \mu \mathrm{m}$ and $131.31 \pm 13.6 \mu \mathrm{m}$, respectively). Increased mean RNFL thickness in COPD patients was thought to be attributed to retinal edema associated with increased hypoxia.

In a 3-month follow-up study done by Ogan [18] to evaluate the short-term impact of COPD on SFCT, and RNFL in two groups of patients. One group of mild-tomoderate cases and another group of advanced cases were recruited. The SFCT in Group two was thinner than Group one and the thickness was significantly reduced during the third month of follow-up.

Generally, in this study and other studies, hypoxia and the ongoing systemic inflammation are thought to be the underlying mechanisms of retinal and choroidal damage in COPD patients and also are thought to influence the OCT measurements. The visual acuity in these patients is affected by the decreased blood flow of the optic nerve head blood flow in choroid. So marked reduction in SFCT in COPD patients is thought to be related to the systemic inflammation and hypoxia caused by the disease.

The oxidative stress emerged from the chronic systemic inflammation and hypoxia in COPD causes disturbance in the balance between the oxidant and antioxidant activity [19]. This may result in ganglion cell death and axonal loss with thinning in RNFL thickness [20]. The relation between the severity of the disease and the degree of thinning of RNFL and SFCT is evident and clarified as the role of the choroidal vasculature in the blood supply of the anterior optic nerve head. It had been represented in different studies [3, 12-18].

Since few retinal investigational studies have been implemented in patients with COPD and the cardiovascular co-morbidities are high in COPD patients, multiple large randomized, and controlled studies are required to better understand the effects of hypoxia on ocular tissues and to emphasize the value of an eye examination for these patients.

The current study as any other study has its own limitations that should be noted. Given the relatively small size of this study sample, there was limited power to confirm the intended correlation well. Also, there was no follow-up to the cases to know how the affection is progressing. Further large-scale studies with follow-up is highly recommended.

\section{Conclusions}

Ocular findings were found to be parts of the systemic manifestations of COPD. More research to clarify the value of an eye examination for COPD patients via a noninvasive procedure with OCT to assess structural and associated functional damage of the retinal microvasculature. These patients should be regularly evaluated regarding ocular pathologies especially those with severe COPD and chronic hypoxia. The ophthalmological examination should be emphasized as a part of the routine follow-up of COPD patients.

\section{Abbreviations \\ COPD: Chronic obstructive pulmonary diseases; GOLD: Global initiative for chronic obstructive lung disease; FEV $_{1}$ : Forced expiratory volume in the first second; EDI-OCT: Enhanced depth imaging optical coherence tomography; FVC: Forced vital capacity; RNFL: Retinal nerve fiber layer; SFCT: Subfoveal choroidal thickness; SD-OCT: Spectral-domain optical coherence tomography.}

\section{Acknowledgements}

All thanks and gratitude to all patients who accepted to participate in the study and all colleagues who helped in the ophthalmological examination.

\section{Authors' contributions \\ NO has put the design of the work and data acquisition and analysis, inter- preted the data, and revised it. YM shared with the physical examination of the patients, data interpretation, and extensively shared in writing the work. HG helped in data analysis and revising it and was a major contributor in writing the manuscript. All authors have read and approved the final manuscript.}

Funding

Not available.

Availability of data and materials

The data sets used during the current study are available from the corresponding author on reasonable request.

\section{Declarations}

Ethics approval and consent to participate

The study was approved by the Ethical Committee Board of Ain Shams University and in accordance with the Declaration of Helsinki (FWA: 00017585) (FMASU R 23 / 2020). An informed written consent was taken from all enrolled patients.

\section{Consent for publication}

Not applicable.

\section{Competing interests}

The authors declare that they have no competing interests.

\section{Author details}

${ }^{1}$ Chest Department, Faculty of Medicine, Ain Shams University, Cairo, Egypt. ${ }^{2}$ Ophthalmology Department, Faculty of Medicine, Ain Shams University, Cairo, Egypt.

Received: 2 March 2021 Accepted: 16 September 2021

Published online: 15 October 2021

\section{References}

1. Ishikawa A (2002) Risk factors for reduced corneal endothelial cell density before cataract surgery. J Cat Refract Surg 28(11):1982-1992 
2. Taşlı NG, Olmez H, Ugurlu A, UçakT, İçel E (2020) Karakurt Y et alAssessment of anterior segment parameters and specular microscopy findings in patients with COPD. Erciyes Med J. 42(1):2066-2070

3. Gok M, Ozer M, Ozen S, Yildirim B (2018) The evaluation of retinal and choroidal structural changes by optical coherence tomography in patients with chronic obstructive pulmonary disease. Curr Eye Res 43(1):116-121

4. Adhi M, Duker J (2013) Optical coherence tomography-current and future applications. Curr Opin Ophthalmol 24(3):213-221

5. Vujosevic S, Martini F, Cavarzeran F, Pilotto E, Midena E (2012) Macular, and peripapillary choroidal thickness in diabetic patients. Retina. 32(9):1781-1790

6. Coskun E, Gurler B, Pehlivan Y, Kisacik B, Okumus S, Yayuspayı R et al (2013) Enhanced depth imaging optical coherence tomography findings in Behcet disease. Ocular Immunology and Inflammation 6(21):440-445

7. Dhoot D, Huo S, Yuan A, Xu D, Srivistava S, Ehlers J et al (2013) Evaluation of choroidal thickness in retinitis pigmentosa using enhanced depth imaging optical coherence tomography. Br J Ophthalmol 97(1):66-69

8. Miller M, Hankinson J, Brusasco V, Burgos F, Casaburi R, Coates A et al (2005 Aug) Standardization of spirometry American Thoracic Society/ European Respiratory Society task force. Eur Respir J 26(2):319-338

9. Global Initiative for Chronic Obstructive Lung Diseases. Global strategy for the diagnosis, management and prevention of chronic obstructive pulmonary disease; 2020. Available at: http://www.goldcopd.com (Accessed on 29 Oct 2020)

10. Ulusoy D, Duru N, Ataş M, Altınkaynak H, Duru Z, Açmaz G (2015) Measurement of choroidal thickness and macular thickness during and after pregnancy. Inter J Ophthalmol 8(2):321-325

11. Sezer T, Altınışık M, Koytak IA, Özdemir MH (2016 Jan) The choroid and optical coherence tomography. Turk J Ophthalmol 46(1):30-37

12. Özçimen M, Sakarya Y, Kurtipek E, Bekci T, Goktas S, Sakarya R et al (2016) Peripapillary choroidal thickness in patients with chronic obstructive pulmonary diseases. Cutan Ocul Toxicol 35(1):26-30
13. Kocamış Ö, Zorlu D (2018) Choroid, and retinal nerve Fiber layer thickness in patients with chronic obstructive pulmonary disease exacerbation. J Ophthalmol 2:1-5

14. Ugurlu E, Pekel G, Altinisik G, Bozkurt K, Can I, Evyapan F (2018) New aspect for systemic effects of COPD: eye findings. Clin Respir J 12(1):247-252

15. Abd El-Naser M, Abd El-Rahman H, Adawy Z, Aly M (2019) Optical coherence tomography study of retinal and Choroidal changes in patients with chronic obstructive pulmonary disease. EJHM. 75(3):2492-2498

16. Alim S, Demir HD, Yilmaz A, Demir S, Güneş A (2019) To evaluate the effect of chronic obstructive pulmonary disease on retinal and Choroidal thicknesses measured by optical coherence tomography. J Ophthalmol 2:79-83

17. Turan M, Gunduz MK, Adam M (2019) The evaluation of retinal nerve Fiber layer thickness by optical coherence tomography in patients with chronic obstructive pulmonary disease. Selcuk Med J 35(4):249-254

18. Ogan N, Ozer PA, Kocamaz MF, Akpinar EE, Baha A, Gulensoy ES (2020) Short-term variations of optic coherence tomography findings in mild and severe chronic obstructive pulmonary disease. Eye. 34:923-933

19. Domej W, Oettl K, Renner W (2014) Oxidative stress and free radicals in COPD implications and relevance for treatment. Int J Chron Obstruct Pulmon Dis 9:1207-1224

20. Lamirel C, Newman N, Biousse V (2010) Optical coherence tomography (OCT) in optic neuritis and multiple sclerosis. Rev Neurol (Paris) 166(12):978-986

\section{Publisher's Note}

Springer Nature remains neutral with regard to jurisdictional claims in published maps and institutional affiliations.

\section{Submit your manuscript to a SpringerOpen ${ }^{\circ}$ journal and benefit from:}

- Convenient online submission

- Rigorous peer review

- Open access: articles freely available online

- High visibility within the field

- Retaining the copyright to your article

Submit your next manuscript at $\boldsymbol{\nabla}$ springeropen.com 